\title{
Применение селективной пайки для изготовления сложной мелкосерийной продукции
}

УДК 621.791 .3 | ВАК 05.27 .06

\author{
В. Кармолин ${ }^{1}$
}

\begin{abstract}
Современный рынок оборудования для производства РЭА пестрит различными решениями, обещающими рост производительности, снижение себестоимости изделий и увеличение прибыли. Фактическая эффективность их внедрения зависит от многих факторов: возможностей и технологических ограничений решения, организации труда, используемых комплектующих и др. Без глубокого анализа целесообразность внедрения и возможная выгода далеко не всегда поддаются адекватной оценке. В данной статье подробно рассматривается тема использования селективной пайки (рис. 1) при единичном и мелкосерийном производстве сложных изделий ответственного назначения. Для производства этого типа характерен консервативный подход к внедрению новых технологий, который в некоторых случаях подкреплен рядом заблуждений, препятствующих выбору и внедрению технологии селективной пайки. Самые распространенные из них мы попытаемся разобрать и развеять.
\end{abstract}

\section{"СЕЛЕКТИВНАЯ ПАЙКА ПОДХОДИТ \\ ТОЛЬКО ДЛЯ МАССОВОГО ПРОИЗВОДСТВА, А У НАС МЕЛКАЯ СЕРИЯ"}

Одним из основных требований к продукции ответственного назначения является ее надежность. Критерием качества пайки штыревых компонентов является качественная галтель с заполнением отверстия припоем не менее чем на 75\% для изделий класса 3 и не менее 50\% для изделий класса 2. Проверить этот параметр возможно с помощью систем рентгеновской инспекции. В случае отсутствия контроля данного вида, приходится рассчитывать лишь на опыт и квалификацию монтажника

Наиболее вероятные причины возникновения дефекта, изображенного на рис. 2: плохая паяемость выводов и контактных площадок, нарушение технологических параметров процесса пайки. Если от проблем с паяемостью выводов и контактных площадок спасает надлежащий входной контроль, то знание и соблюдение параметров и режимов пайки напрямую зависит от конкретного монтажника. Его работа осложняется еще и тем, что визуальный контроль качества пайки при ручных операциях затруднен, так как паяные соединения закрыты корпусом разъема.

ООО "Остек-СМТ», руководитель проектов,

karmolin.v@ostec-group.ru.
Решить подобные проблемы помогает технология селективной пайки. Одним из наиболее ярких примеров преимуществ ее применения, вне зависимости от серийности продукции, является сборка кросс-плат с большим количеством многовыводных разъемов (рис. 3). Для пайки двадцати 96-выводных разъемов

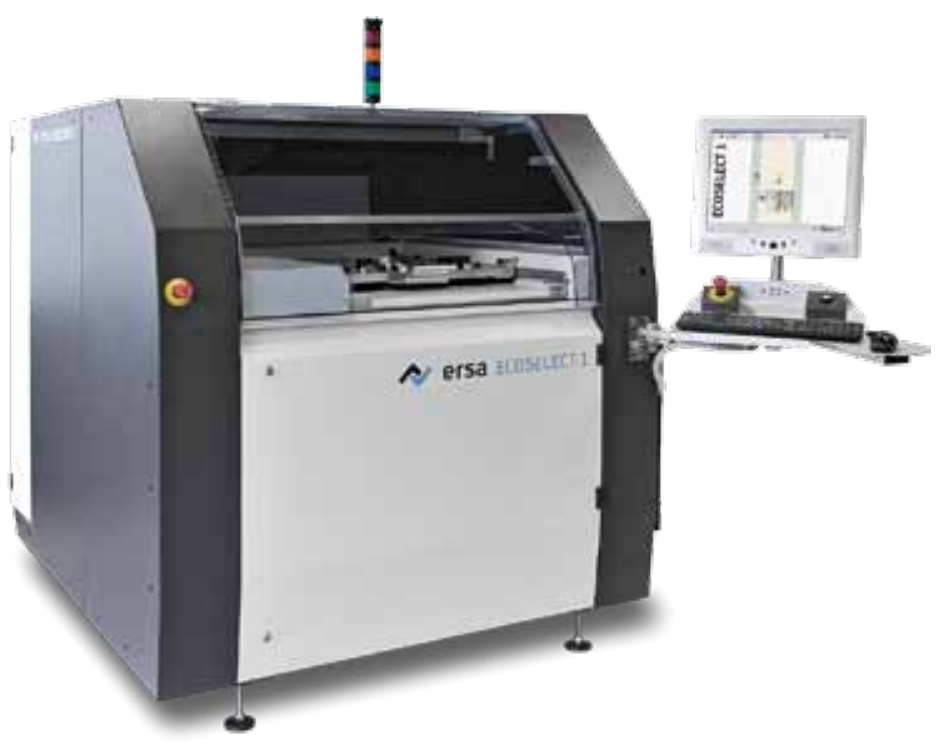

Рис. 1. Пример современной установки селективной пайки для мелкосерийного производства 


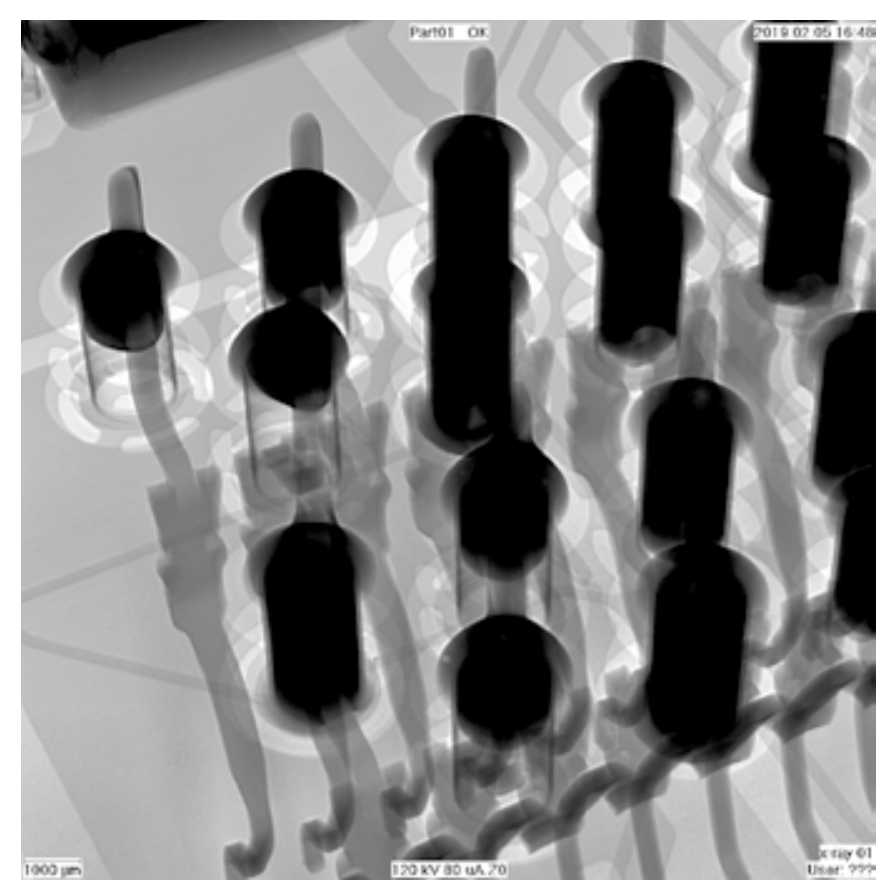

Рис. 2. Последствия нарушения режимов пайки (отсутствие протекания и заполнения припоем отверстий)

вручную опытному электромонтажнику потребуется, по крайней мере, $(20 \times 96 \times 3 / 0,7) / 60=137$ мин (3 с затрачивается на пайку одного вывода, 0,7 - коэффициент, обозначающий время, которое монтажник не тратит непосредственно на пайку). На самом деле трудоемкость будет существенно больше, так как при пайке выводов разъемов на многослойную печатную плату необходимо увеличить время пайки каждого соединения и делать паузы, чтобы восстановилась заданная температура жала паяльника. При этом трудно добиться хорошей повторяемости и качества паяных соединений.

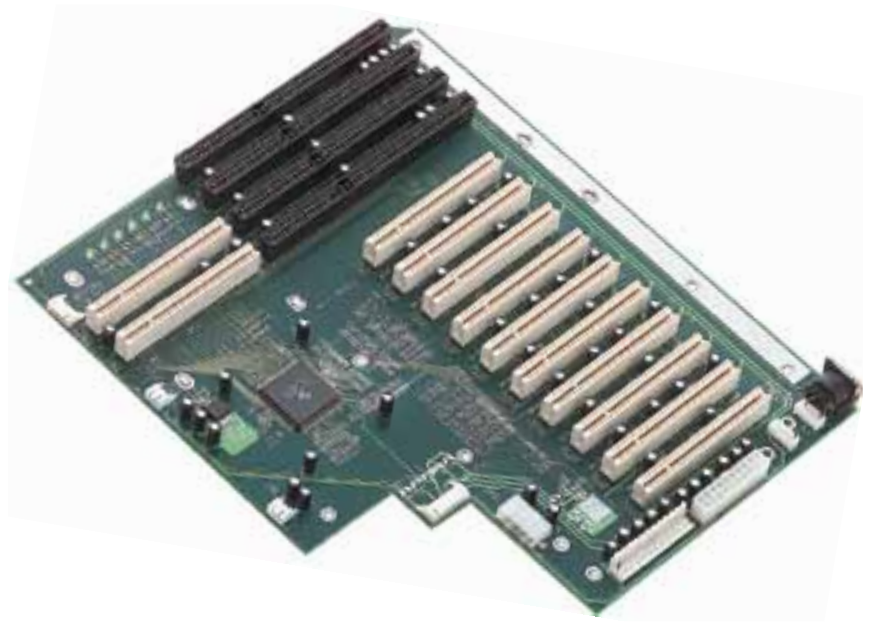

Рис. 3. Кросс-плата
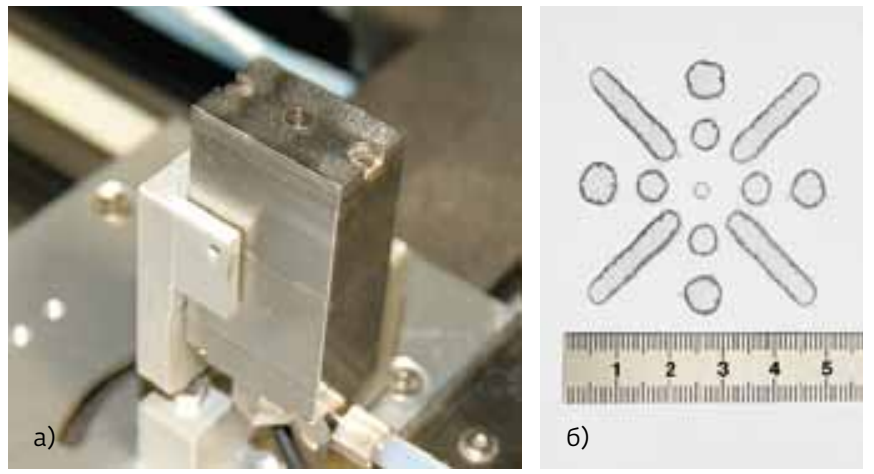

Рис. 4. Прецизионный каплеструйный флюсователь (а) и результаты тестового точечного флюсования и флюсования линией, с акцентом на диаметр участков (б). Диаметр нанесенного участка - от 3 мм, программируемый объем нанесения флюса для каждой точки пайки

Применение современных систем селективной пайки позволяет повысить производительность на операции пайки многорядных разъемов, монтируемых в отверстия печатной платы, в 3-10 раз, в зависимости от сложности изделий и конфигурации установки. В мелкосерийном производстве селективная пайка находит свое применение за счет возможности программирования и поддержания параметров процесса для каждого паянного соединения, азотной среды, точного селективного флюсования (рис. 4), качественного подогрева (предварительного и в зоне пайки) (рис. 5). Благодаря этим преимуществам обеспечивается хорошая повторяемость процесса, гарантируется высокое качество и надежность печатных узлов.

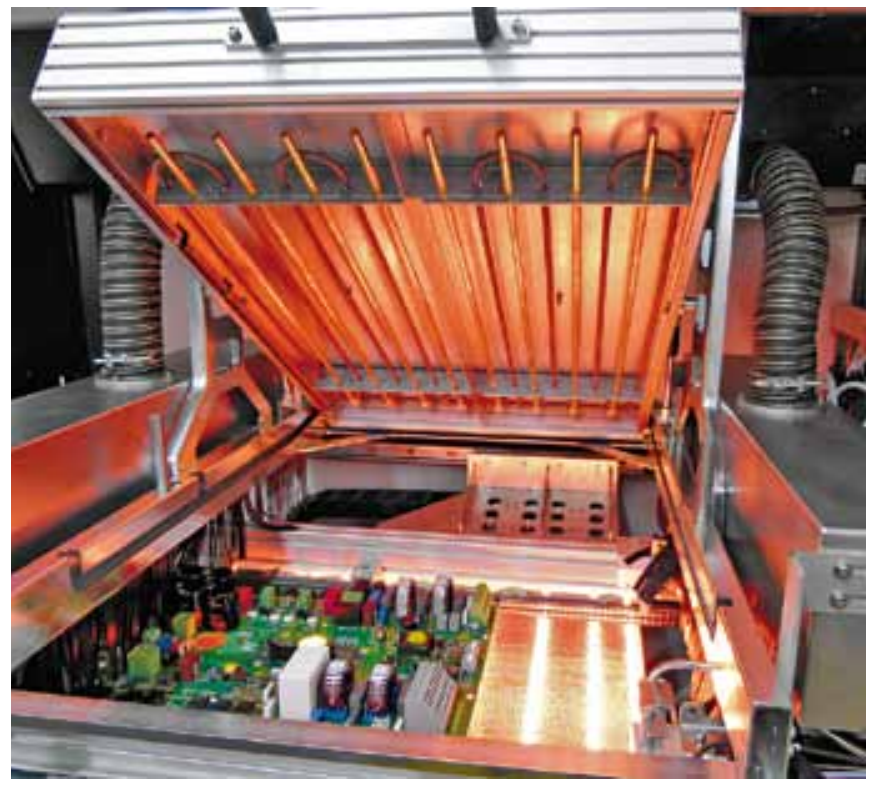

Рис. 5. Верхний и нижний предварительный нагрев 


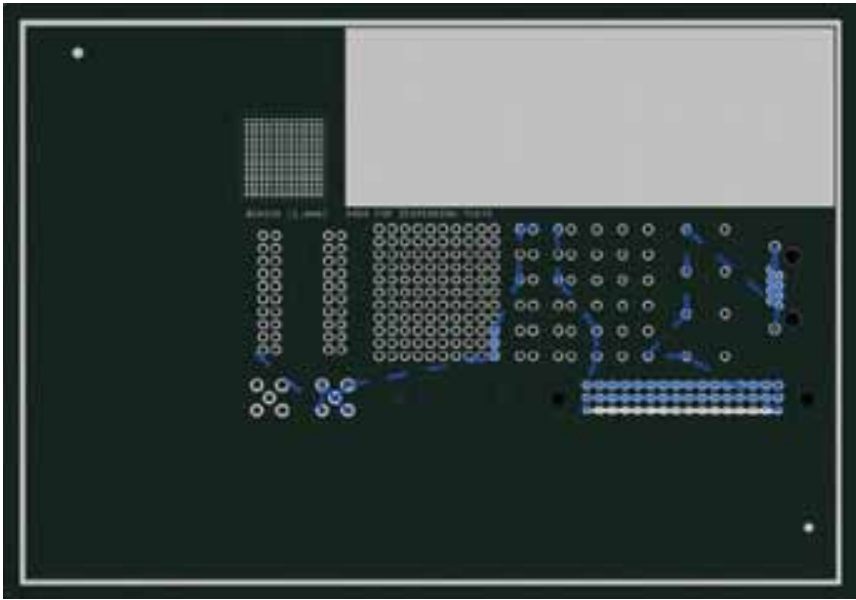

Рис. 6. Программирование цикла флюсования

\section{«У НАС БОЛЬШАЯ НОМЕНКЛАТУРА, МНОГО ВРЕМЕНИ УЙДЕТ \\ НА НАПИСАНИЕ ПРОГРАММ»}

Рассмотрим процесс программирования на примере программного обеспечения компании Ersa. Создание программ пайки производится на основании фотографии, скана или чертежа печатной платы. После импорта изображения платы и ввода технологических параметров процесса оператору остается лишь указать точки/линии флюсования (рис. 6) и пайки (рис. 7) на поверхности печатного узла. При этом программа произведет оптимизацию перемещения флюсователя и ванны с припоем таким образом, чтобы исключить задевание установленных с нижней стороны высоких компонентов и оптимизировать общий цикл пайки печатного узла. Все проложенные треки флюсования и пайки можно легко оценить при помощи 3D-визуализации платы. Для каждой точки пайки могут быть заданы индивидуальные параметры процесса (рис. 8). В установках фирмы Ersa подготовка программ пайки может происходить удаленно, полностью в режиме "офлайн".

Длительность написания программы для тестовой платы, изображенной на рис. 6 и 7, составила 5 мин. Для реальных изделий анализ печатного узла, программирование точек пайки с различной теплоемкостью и отладка программы в среднем занимает от 1 до 24 в зависимости от сложности печатного узла.

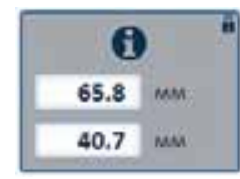
платы

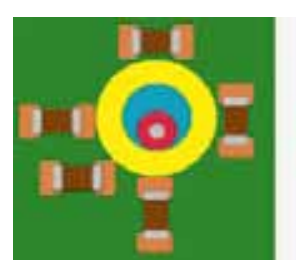

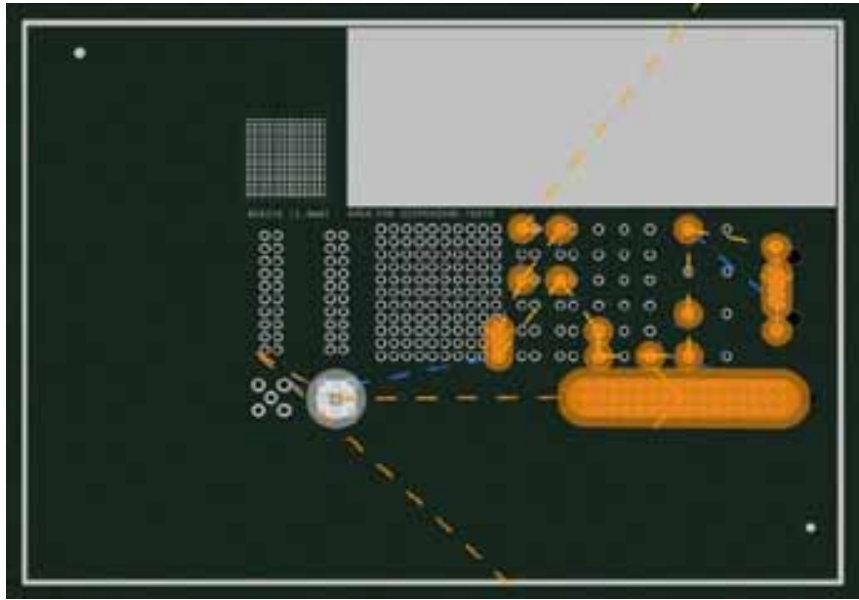

Рис. 7. Программирование цикла пайки

\section{«ТЕХНОЛОГИЧЕСКИЕ ОГРАНИЧЕНИЯ, НУЖНО ПОВТОРНО РАЗВОДИТЬ ПЛАТЫ॥}

Мелкосерийное производство напрямую связано с темой разработки и прототипирования. Важнейшим вопросом при внедрении любой технологии является адаптация новых разработок и существующих изделий к технологическим требованиям для их сборки. В случае, если этот процесс будет слишком трудоемким, все остальные преимущества окажутся неважны.

Как и любая другая технология, селективная пайка предъявляет свои требования к конструкции печатных узлов. Эти требования достаточно просты и в основном сводятся к свободному пространству вокруг паяных соединений штыревого компонента, подлежащего пайке (рис. 9).
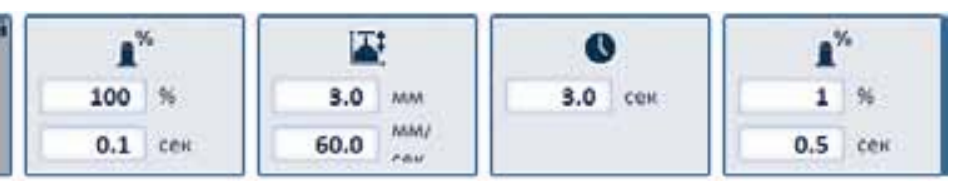

Рис. 8. Программирование параметров процесса для отдельных участков
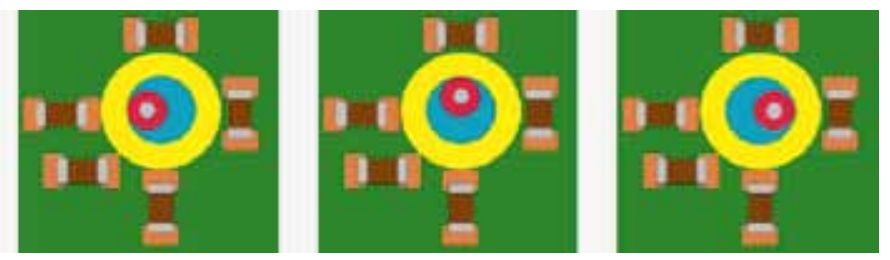

Рис. 9. Требования к конструктиву печатного узла для селективной пайки. Минимальная зона (желтая), свободная от компонентов: ø5 мм; минимальная зона (синяя), необходимая для процесса селективной пайки: 5-(1,5+1,5)=2 мм; размер монтажной площадки: ø2 мм 
Для некоторых изделий изменение конструктива изделия не представляется возможным и приходится маскировать поверхностно монтируемые компоненты либо наиболее проблемные участки допаивать вручную. Пример такого случая приведен на рис. 10. При пайке селективной установкой в этом случае возможно либо смывание SMD-компонента во время процесса пайки, либо велика вероятность образования перемычек припоя между выводами или контактными площадками (рис. 11).

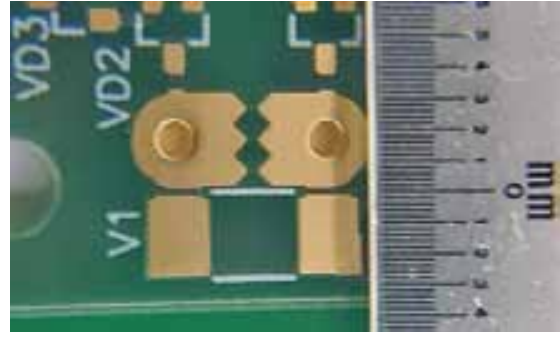

Рис. 10. Пример непродуманной конструкции печатного узла (слишком малое расстояние между контактными площадками)

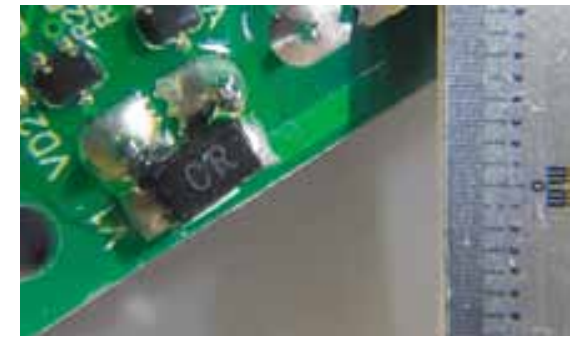

Рис. 11. Дефект пайки

(образование перемычек из припоя)
Использование преимуществ селективной пайки позволяет разработчикам применять тяжелые трансформаторы, мощные реле, транзисторы и тем самым улучшать технические характеристики продукта. С другой стороны, появляется возможность уменьшить габариты изделия за счет использования плат с бо́льшим числом слоев, сочетания, например, блока питания и блока обработки сигналов на одной плате и т. п. Исполнение требований к свободному пространству вокруг зоны пайки и использованию контактных площадок минимального размера лишь в редких случаях может ограничивать разработчиков печатных узлов, при этом позволяет получить стабильные и качественные результаты пайки и дать определенную гибкость при проектировании и последующей сборке печатного узла.

\section{"СЕЛЕКТИВНАЯ ПАЙКА - ЭТО ДОРОГО"}

В табл. 1 приведены результаты упрощенного расчета окупаемости внедрения установки селективной пайки для одного из проектов Остек-СМТ. В данном случае участок ручной пайки состоит из шести человек со средней ставкой монтажника 200 руб. / . За смену необходимо произвести пайку 30 изделий.

В данном примере наглядно иллюстрируется тот факт, что окупаемость установки происходит за счет экономии на фонде оплаты труда и ремонте изделий. Видно, что при использовании селективной пайки средняя экономия фонда оплаты труда, в нашем случае, составляет 1641600 руб. в год, а средняя экономия на ремонте изделий - 1111500 руб. в год. Стоимость внедрения системы селективной пайки равна 11 млн руб., соответственно срок возврата инвестиций на ее внедрение составляет четыре года.
В расчете не учтены многие факторы, такие как стоимость материалов и оснащение рабочих мест для ручных операций, возможности предприятия выполнять заказы по контрактному производству за счет запаса производительности и т.п., так как эти факторы слишком сильно зависят от конкретного производства и индивидуально рассчитываются в каждом отдельном случае.

\section{"У НАС СВОЯ СПЕЦИФИКА ПРОИЗВОДСТВА, МЫ НЕ ЕВРОПА И НЕ КИТАЙ"}

Любое предприятие, вне зависимости от того, производит оно крупносерийную бытовую электронику либо единичные платы для систем ответственного назначения, должно держать руку на пульсе, чтобы быть конкурентоспособным как на российском, так и на мировом рынке.

Невозможно следовать современным тенденциям, например, усложнению конструкции изделий, повышенным требованиям к качеству и увеличенной плотности монтажа, без изменений в технологии производства. Человеку все сложнее становится на должном уровне выполнять те операции, которые успешно выполняют машины. Именно по этим причинам, производители современных

Таблица 1. Сравнительные характеристики ручной и селективной пайки

\begin{tabular}{|c|c|c|}
\hline Наименование & $\begin{array}{r}\text { Участок } \\
\text { ручной } \\
\text { пайки }\end{array}$ & $\begin{array}{r}\text { Участок } \\
\text { селективной } \\
\text { пайки }\end{array}$ \\
\hline Цикл пайки одного изделия, с & 310 & 90 \\
\hline Средний процент брака, \% & 5 & 2 \\
\hline $\begin{array}{l}\text { Средняя стоимость ремонта изделия, включая } \\
\text { диагностику, руб. }\end{array}$ & 5000 & 5000 \\
\hline $\begin{array}{l}\text { Фонд оплаты труда для участка в год, руб. } \\
\text { (включая заработную плату, выплаты } \\
\text { за отпуска, простои, больничные и т.д.) }\end{array}$ & 3283200 & 1641600 \\
\hline Затраты на ремонт изделий за один год, руб. & 1852500 & 741000 \\
\hline
\end{tabular}


установок для селективной пайки одинаково успешно внедряют их на производствах различных типов, в разных странах, в том числе и в России.

$$
\therefore \leqslant
$$

Подводя итог, можно сказать, что технология селективной пайки находит свое применение при изготовлении сложной мелкосерийной и ответственной продукции. За счет качественной пайки различных печатных плат (многослойных, с высокой теплоемкостью, с плотным двухсторонним монтажом), хорошей повторяемости и стабильности процесса, удается добиться высокой надежности изготавливаемой продукции. Это особенно актуально, когда производитель гарантирует срок службы своих изделий более 10 лет. При сборке прототипов селективная пайка уменьшает общие трудозатраты и ускоряет цикл разработки за счет того, что уменьшается количество технологических дефектов и разработчику не приходится долго "отлавливать" дефекты сборки. Например, селективное нанесение флюса обеспечивает лучшую чистоту поверхности платы, по сравнению с ручной пайкой. Как следствие, меньше токов утечки, паразитных наводок и "головной боли" на этапе настройки и регулировки.

Безусловно, целесообразность и эффективность внедрения технологии селективной пайки зависит от особенностей производства и перспективность перехода на данную технологию нужно оценивать в каждом конкретном случае.

\section{КНИГИ ИЗДАТЕЛЬСТВА «ТЕХНОСФЕРА»}

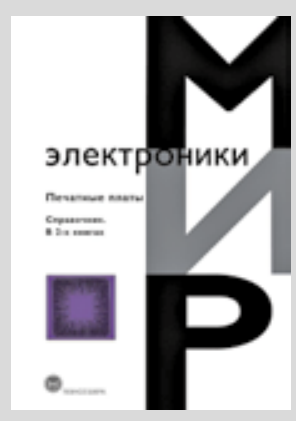

Цена 2600 руб. за два тома

\section{ПЕЧАТНЫЕ ПЛАТЫ. СПРАВОЧНИК В 2-Х КНИГАХ}

\section{Под ред. К. Кумбза}

В издании рассматриваются все процессы создания и применения печатных плат: проектирование и выбор базовых материалов, изготовление, обеспечение качества и оценки надежности печатных плат и печатных узлов, монтаж плат, включая особенности бессвинцовых технологий пайки, а также методы и средства испытаний применительно к специальным требованиям. Шестое издание дополнено информацией по ценообразованию, количественной оценке технологичности плат, управлению производством и решению экологических проблем.

Все изменения в технологии изготовления печатных плат нашли свое отражение в этой книге, что привело к тому, что более 75\% ее глав были либо исправлены, либо являются новыми, свидетельствуя, что шестое издание содержит самую последнюю информацию.

Цель книги состоит в том, чтобы предоставить нужную информацию насколько возможно в более конкретном и подробном виде, используя промышленные стандарты там, где они существуют, и передовой опыт, имеющий технологическое обоснование и продемонстрировавший свою работоспособность там, где соответствующих стандартов нет

Справочник рассчитан на широкий круг специалистов-технологов, конструкторов, схемотехников и специалистов по надежности, поскольку печатные платы являются фундаментом проектирования и производства изделий электроники.

Данная книга может служить учебным пособием для студентов и аспирантов вузов соответствующих специальностей. 
16-Й МОСКОВСКИЙ МЕЖДУНАРОДНЫЙ

ИННОВАЦИОННЫЙ ФОРУМ И ВЫСТАВКА

ТОЧНЫЕ ИЗМЕРЕНИЯ ОСНОВА КАЧЕСТВА И БЕЗОПАСНОСТИ
MetrolExpo'2020 Москва, 2-4 июня вднХ, павильон 75

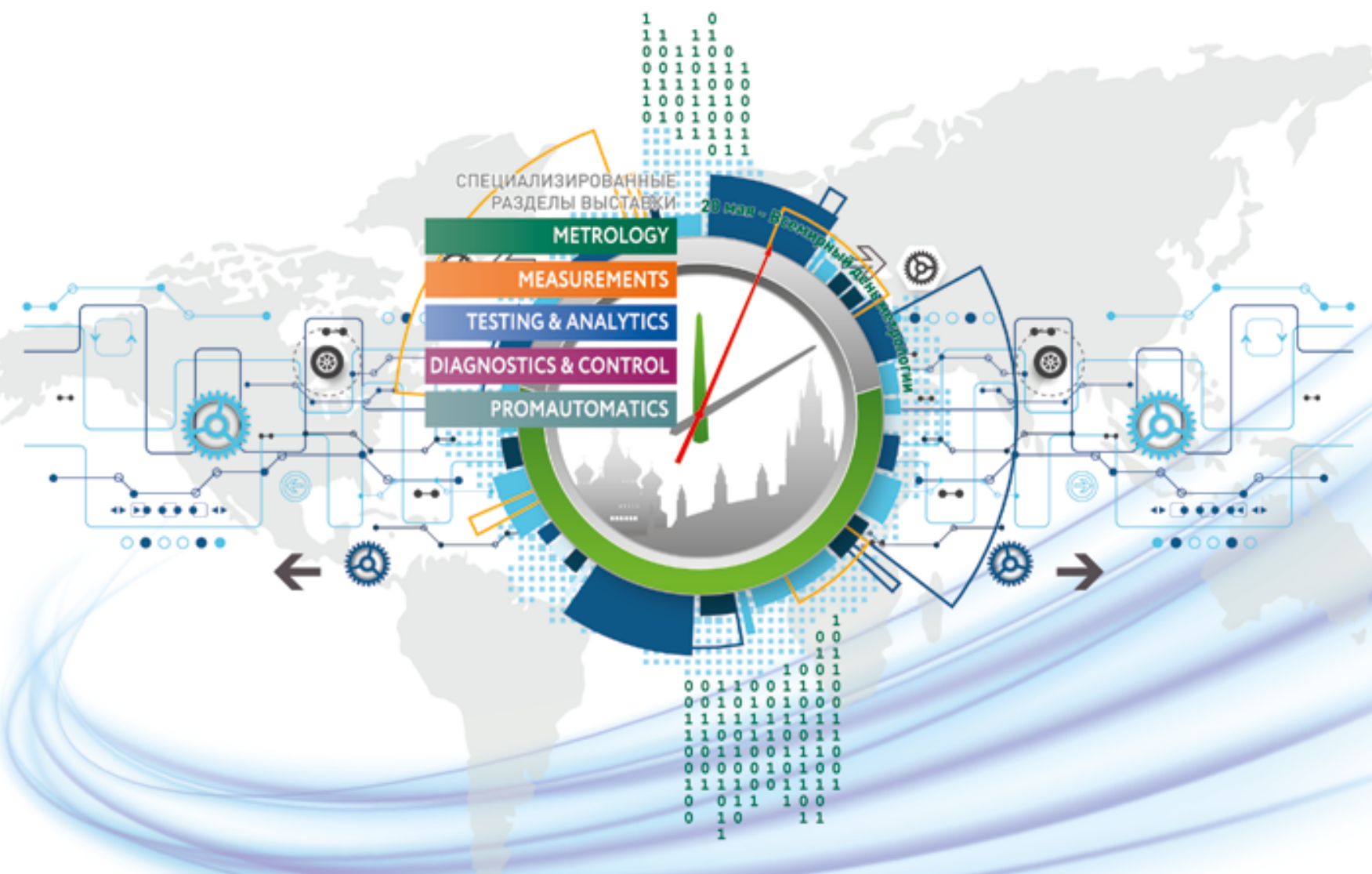

ТЕМАТИЧЕСКИЕ РАЗДЕЛЫ ВЫСТАВКИ:
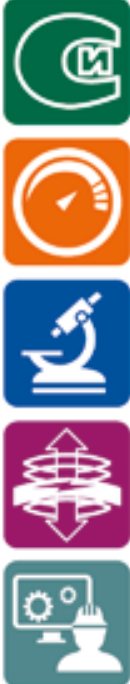

МЕТРОЛОГИЯ

METROLOGY

ИЗМЕРЕНИЯ

MEASUREMENTS

ИСПЫТАНИЯ И АНАЛИТИКА

TESTING \& ANALYTICS

ДИАГНОСТИКА И КОНТРОЛЬ

DIAGNOSTICS \& CONTROL

АВТОМАТИЗАЦИЯ

PROMAUTOMATICS
Устроитель:

Выставочная компания вЭСтстрОЙ ЭКСпо
ПРИГЛАШАЕМ ПРИНЯТЬ УЧАСТИЕ

www.metrol.expoprom.ru
口玈口 $>0$ 1: a난 
TEХНОСФЕРА

РЕКЛАМНО-ИЗДАТЕЛЬСКИЙ ЦЕНТР

\section{0\% ГАРАНТИЯ ПОЛУЧЕНИЯ ВСЕХ НОМЕРОВ}

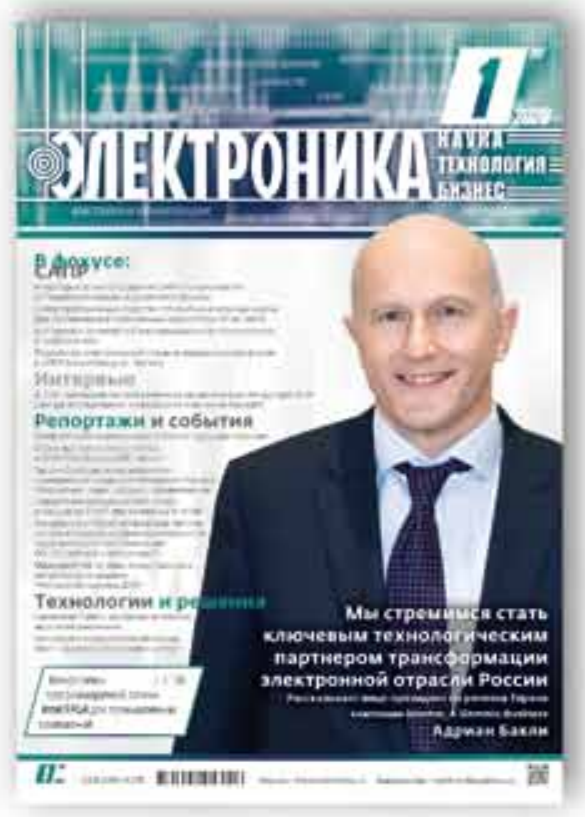

Стоимость 2200 р. за номер

Периодичность: 10 номеров в год www.electronics.ru

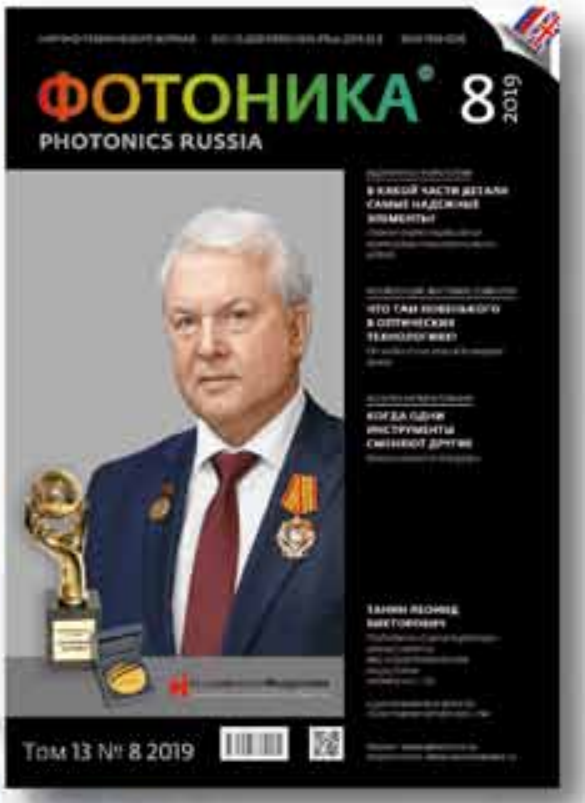

Стоимость 1430 p. за номер

Периодичность; 8 номеров в год www.photonics.su

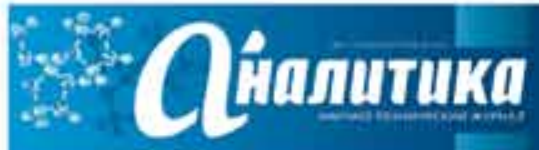

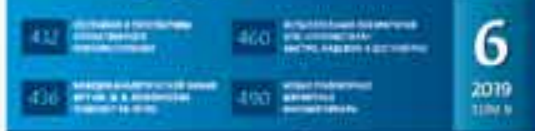

Cubis" II

$\triangle$

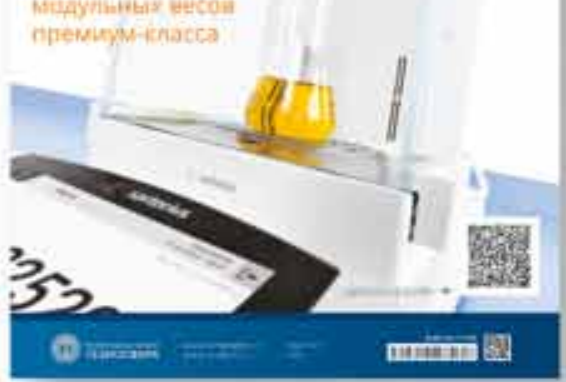

Стоимость 1430 р. за номер

Периодичность: 6 номеров в год www.j-analytics.ru

\section{ПОДПИСКА НА ЖУРНАЛЬ}

www.technosphera.ru

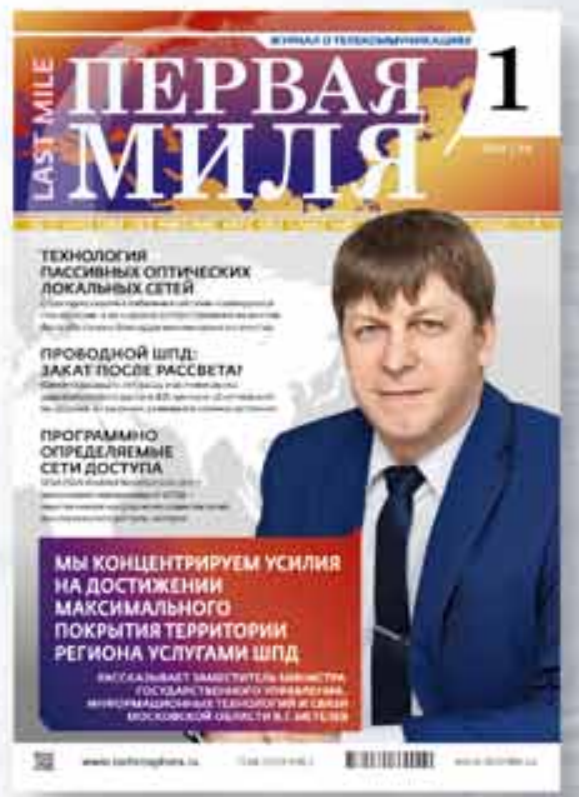

Стоммость 1056 p. за номер

Периодичность: 8 номеров в год www.lastmile.su

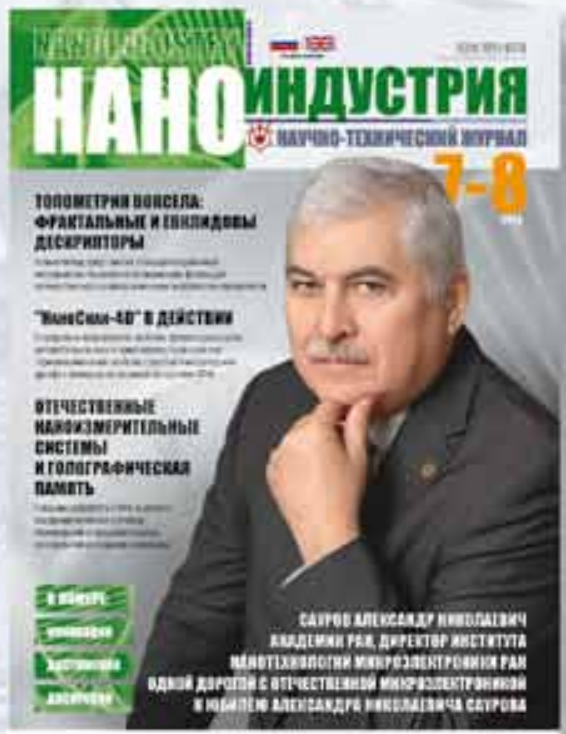

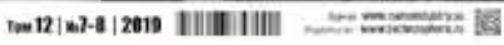

Стоимость 1287 р. за номер

Периодичность: 8 номеров в год

www.nanoindustry.su

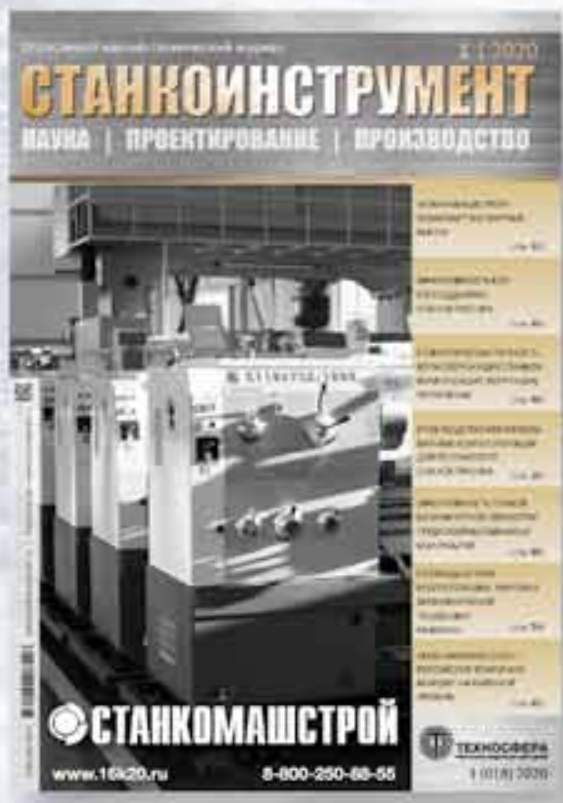

Стоимость 1716 р. за номер

Периодичность: 4 номера в год www.stankoinstrument.su 